Roberta Bouchardet

\title{
A Imaginação na Teoria da Mente segundo Hume \\ Uma análise a partir do Livro I do Tratado
}

Dissertação de Mestrado

Dissertação apresentada ao Departamento de Filosofia da PUC-Rio, como parte dos requisitos para a obtenção do grau de mestre em Filosofia.

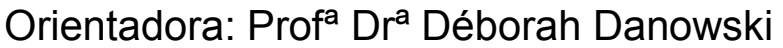




\title{
Roberta Bouchardet
}

\section{A Imaginação na Teoria da Mente segundo Hume \\ Uma análise a partir do Livro I do Tratado}

\begin{abstract}
Dissertação
apresentada

ao

Departamento de Filosofia da PUC-Rio, como parte dos requisitos para a obtenção do grau de mestre em Filosofia. Aprovada pela Comissão Examinadora abaixo assinada.
\end{abstract}

\author{
Prof ${ }^{a}$ Déborah Danowski \\ Orientadora \\ Departamento de Filosofia - PUC-Rio
}

Prof. Luiz Carlos Pinheiro Dias Pereira

Departamento de Filosofia - PUC-Rio

Prof. Ulysses Pinheiro

Departamento de Filosofia do Instituto de Filosofia e Ciências Sociais - UFRJ

Prof. Carlos Alberto Gomes dos Santos

Departamento de Filosofia - PUC-Rio

(Suplente)

Prof. Paulo Fernando Carneiro de Andrade Coordenador Setorial de Pós-Graduação do Centro de Teologia e Ciências Humanas - PUC-Rio

Rio de Janeiro, 07 de abril de 2006. 
Todos os direitos reservados. É proibida a reprodução total ou parcial do trabalho sem autorização da autora, da orientadora e da universidade.

Roberta Lima Silva Bouchardet Graduou-se em Ciência da Computação na Universidade Federal de Minas Gerais em 1990. Cursou pósgraduação em Administração Financeira na Fundação Dom Cabral em Belo Horizonte, em 1994, e em Metodologia do Ensino Superior na Fundação Getúlio Vargas em 2005. Interessou-se pela Filosofia na UFMG, onde começou a estudar e se interessou pelos temas relacionados à Teoria do Conhecimento, Filosofia da Ciência e Filosofia da Mente. Trabalhou como Analista de Sistemas em indústrias como a Cia. de Fiação e Tecidos Cedro Cachoeira e Alimenta - Alimentação Industrial. Foi funcionária da Secretaria de Estado da Fazenda de Minas Gerais até 2003.

Ficha catalográfica

Bouchardet, Roberta

A imaginação na teoria da mente segundo Hume: uma análise a partir do Livro I do Tratado / Roberta Bouchardet ; orientadora: Déborah Danowski. - Rio de Janeiro : PUC, Departamento de Filosofia, 2006.

97 f. : il. ; $30 \mathrm{~cm}$

Dissertação (mestrado) - Pontifícia Universidade Católica do Rio de Janeiro, Departamento de Filosofia

Inclui bibliografia.

1. Filosofia - Teses. 2. Imaginação. 3. Memória. 4. Razão. 5. Mente. 6. Crença. 7. Conhecimento. 8. Hume, David, 1771-1776. I. Danowski, Déborah. II. Pontifícia Universidade Católica do Rio de Janeiro. Departamento de Filosofia. III. Título. 
Aos meus pais, que me acolheram nesta vida e me incentivaram e apoiaram sempre, sem nunca cobrar nada.

Ao meu companheiro Claudio, que não me deixa desistir perante as dificuldades e pela confiança constante. 


\section{Agradecimentos}

Muitos foram os que estiveram presentes na jornada deste trabalho, que se iniciou na Universidade Federal de Minas Gerais, em Belo Horizonte, e terminou na PUC, do Rio de Janeiro. A todos manifesto meus sinceros agradecimentos.

À Prof ${ }^{\mathrm{a}}$ Déborah, pela dedicação, orientação e paciência durante a concretização deste trabalho.

À Prof ${ }^{\mathrm{a}}$ Lívia Guimarães, que despertou meu interesse pela obra de David Hume, na UFMG, e me apoiou no início das pesquisas.

Ao CNPQ e à PUC-Rio, pelos auxílios concedidos para a realização desta pesquisa.

Aos professores das disciplinas do mestrado em filosofia, pelas ricas discussões em sala de aula e contribuições para meu entendimento dos temas da filosofia.

Aos funcionários da PUC-Rio, pelas orientações quanto ao encaminhamento e regras da Universidade e pela pronta disponibilidade.

Aos colegas de mestrado, pela convivência, trocas de idéias e discussões nos cafés da PUC, em especial à colega Raquel, que, mesmo à distância, me ajudou em muitas situações.

A todos que, direta ou indiretamente, contribuíram para a realização deste trabalho. 


\section{Resumo}

Bouchardet, Roberta; Danowski, Déborah. A Imaginação na teoria da mente segundo Hume: uma análise a partir do Livro I do Tratado. Rio de Janeiro, 2006. 97p. Dissertação de Mestrado - Departamento de Filosofia, Pontifícia Universidade Católica do Rio de Janeiro.

Esta dissertação tem como tema o conceito de "imaginação" no Livro I do Tratado da Natureza Humana, de David Hume. A plena compreensão desse conceito é fundamental para a análise do modelo de mente presente na teoria humeana sobre o entendimento humano, em virtude do papel fundamental ali desempenhado por essa faculdade. Sempre restringindo-se àquela obra, o presente trabalho discute os vários sentidos do termo "imaginação", por meio de uma análise das diversas funções exercidas por essa faculdade, e, ainda, por uma comparação com outras faculdades da mente, como a memória e a razão.

\section{Palavras-chaves}

Imaginação; Memória; Razão; Mente; Crença; Conhecimento; David Hume. 


\section{Abstract}

Bouchardet, Roberta; Danowski, Déborah (Advisor). The Imagination in Hume's mind theory: an analysis from Treatise Book I. Rio de Janeiro, 2006. 97p. MSC. Dissertation - Departamento de Filosofia, Pontifícia Universidade Católica do Rio de Janeiro.

This thesis is about the concept of "imagination" in Book I of David Hume's Treatise of Human Nature. A full understanding of this concept is of fundamental importance to the analysis of the mind model contained in Hume's theory of human understanding, due to the central role there played by that faculty. While restricting ourselves to that text, we discuss the several senses of the term "imagination", by analysing the different functions of that faculty, and by comparing it with other faculties of the mind, such as memory and reason.

\section{Keywords}

Imagination; Memory; Reason; Mind; Belief; Knowledge; David Hume. 


\section{Sumário}

Lista de figuras

Pág.

10

$\begin{array}{ll}\text { Observações sobre notações } & 11\end{array}$

Introdução

Capítulo 1:

Imaginação e formação de crenças no modelo de mente $\begin{array}{ll}\text { de Hume } & 18\end{array}$

1. A mente humana segundo o modelo humeano 18

2. Imaginação e formação de crença 22

2.1. Os sentidos de imaginação para Hume 23

2.2. O papel da imaginação na formação de crença através das inferências causais 29

2.3. O papel da imaginação na formação de outras crenças 34

3. Propriedades da imaginação 38

4.A força e vividez das ficções da imaginação 39

\section{Capítulo 2:}

Imaginação e Memória $\quad 41$

1.Importância da distinção entre imaginação e memória 41

2.Distinção entre imaginação e memória 43

2.1. Critérios de distinção $\quad 44$

2.1.1. Critério de liberdade de associação 45

2.1.2. Critério de força e vividez 52

2.1.3. Conseqüência da distinção entre força e vividez $\quad 59$

3. A memória fundada na imaginação 63

\section{Capítulo 3:}

Imaginação e Razão 68

1.A Razão no Livro I do Tratado $\quad 69$

2.As relações que formam o nosso raciocínio 73

2.1. A influência da reflexão nos raciocínios e nas crenças 74

3.Raciocínios Prováveis e Probabilidade 77 
3.1. As distinções da razão, segundo o grau de evidência

3.2. O funcionamento da Imaginação no caso das experiências contrárias $\quad 80$

3.3. Outras influências sobre os raciocínios prováveis 81

3.4. A imaginação funcionando através das regras gerais 82

4. Comparações entre imaginação e razão 84

5. A razão, ou o entendimento, fundada na imaginação 86

$\begin{array}{ll}\text { Conclusão } & 88\end{array}$

$\begin{array}{ll}\text { Bibliografia } & 92\end{array}$

Índice Remissivo 96 


\section{Lista de Figuras}

Pág.

Figura 1 - Imaginação oposta à memória 30

Figura 2 - Imaginação oposta à razão e à memória 30

Figura 3 - Imaginação segundo princípios regulares ou irregulares $1 \quad 33$

Figura 4 - Imaginação segundo princípios regulares ou irregulares $2 \quad 34$

Figura 5 - Imaginação segundo princípios regulares ou irregulares $3 \quad 34$ 


\section{Observações quanto a notações e referências bibliográficas:}

As referências usadas ao longo deste trabalho são, em grande parte, do Tratado da Natureza Humana, de David Hume. Várias edições foram usadas: a edição em Inglês de Selby-Bigge, a edição em Português da UNESP e a edição eletrônica da Project Gutenberg Litterary Archive Foundation (os dados completos se encontram na bibliografia).

As páginas e referências usadas no texto são da edição em inglês, com as devidas traduções em notas de rodapé. Para não tornar muito repetitivas as referências ao Tratado e suas respectivas partes e seções, foi usada a seguinte padronização:

- $\mathrm{T}=$ Treatise of Human Nature: HUME, David. A Treatise of Human Nature. Ed. Selby-Bigge. Oxford, 1888. Reimp. London: Penguin Books, 1985.

- Os números em algarismos romanos seguintes se referem ao livro, parte e seção da obra, respectivamente.

- O número em algarismos arábicos a seguir se refere à página da edição em inglês utilizada. Nessa edição não há numeração dos parágrafos.

- $\quad \mathrm{TP}=$ Tratado da Natureza Humana (edição em Português): HUME, David. Tratado da Natureza Humana. Trad. Déborah Danowski. São Paulo: UNESP, 1999.

- Os números em algarismos romanos seguintes se referem ao livro, parte e seção da obra, semelhantemente à referência em inglês.

- Nas traduções, ao invés de utilizar o número da página, utilizo o número do parágrafo, disponível nessa edição, por considerar mais útil à localização do texto.

Exemplo:

T I. IV. IV, p. 225 equivale a:

A Treatise of Human Nature, edição acima, livro I, parte IV, seção IV, página 225.

E corresponde a TP I. IV. IV, §1, que equivale a:

Tratado da Natureza Humana, edição em português acima, livro I, parte IV, seção IV, parágrafo $1^{\circ}$.

Na seção "Bibliografia" encontram-se as referências das obras consultadas para o trabalho. Algumas foram diretamente usadas no trabalho, outras serviram de subsídios ao entendimento geral da obra de Hume. Aquelas diretamente usadas foram citadas ao longo do texto e serão facilmente identificadas. 
"É inútil tentar fazer um homem abandonar pelo raciocínio uma coisa que não adquiriu pela razão." (Jonathan Swift) 